\title{
Analysis of Mineral Density of Calcified Tissues in Children with X-Linked Hypophosphatemic Rickets and Hypophosphatasia Using Cone Beam Computed Tomography Data
}

\author{
Dmitriy A. Lezhnev, PhD, ScD; Elena V. Vislobokova*; Larisa P. Kiselnikova, PhD, ScD; \\ Natalia A. Sholokhova, PhD; Margarita V. Smyslenova, PhD, ScD; Viktor P. Truten, $\mathrm{PhD}, \mathrm{ScD}$ \\ Moscow State University of Medicine and Dentistry named after AI Evdokimov \\ Moscow, Russia
}

\begin{abstract}
The purpose of the present cohort study was a quantitative assessment of the enamel, dentin, and alveolar bone mineral density (BMD) using Cone Beam Computed Tomography (CBCT) scans in patients with X-linked hypophosphatemic rickets (HLHR) and hypophosphatasia (HPP) and a comparison with the data obtained from the control group.

Methods and Results: The unrepresentative, non-random sample included 30 CBCT scans of children with genetically and biochemically confirmed XLHR (OMIM \#307800) and HPP (OMIM: 146300, 241510, 241500, and 146300). X-ray examination and dental care were carried out in the Radiology Diagnostics Department and Pediatric Dentistry Department at Moscow State University of Medicine and Dentistry named after AI Evdokimov. The mineral density of calcified tissues (enamel, dentin, and alveolar bone) was evaluated using i-CAT Vision TM software options on reconstructed CBCT axial views.

The images of all XLHR and HPP patients visualized large pulp chambers with prominent pulp horns extending to the dentin-enamel junction. The present study revealed poor alveolar bone mineralization in patients with HPP and XLHR. Analysis of CBCT scans showed a significant dentine hypodensity in XLHR patients, which may contribute to the emergence of multiple, spontaneous, periapical abscesses spreading rapidly in the jawbone.

Conclusion: Data obtained could be used for planning dental treatment of patients with XLHR and HPP. (International Journal of Biomedicine. 2021;11(1):53-57.)

Key Words: X-linked hypophosphatemic rickets $\bullet$ hypophosphatasia $\bullet$ mineral density $\bullet$ cone beam computed tomography

For citation: Lezhnev DA, Vislobokova EV, Kiselnikova LP, Sholokhova NA, Smyslenova MV, Truten VP. Analysis of Mineral Density of Calcified Tissues in Children with X-Linked Hypophosphatemic Rickets and Hypophosphatasia Using Cone Beam Computed Tomography Data. International Journal of Biomedicine. 2021;11(1):53-57. doi:10.21103/Article11(1)_OA11
\end{abstract}

\section{Abbreviations}

BMD, bone mineral density; DMD, dentin mineral density; CBCT, cone beam computed tomography; XLHR, X-linked hypophosphatemic rickets; HPP, hypophosphatasia.

\section{Introduction}

Genetic disorders affecting bone mineralization cause skeleton deformities and significant bone osteoporosis. Similar problems in this cohort of patients were also identified in the maxillofacial region. ${ }^{(1)}$ Disruption of the formation processes of calcified tissues (enamel, dentin, cement, and alveolar bone) causes different dental manifestations of diseases. X-linked hypophosphatemic rickets (XLHR, OMIM \#307800) is a genetically determined disorder characterized by poor bone mineralization, dental abnormalities and multiple abscesses associated with caries-free teeth (Fig.1a-b). Impairment 
of mineralization is the direct consequence of disrupted homeostasis of phosphate-caused mutations in the phosphateregulating gene $(P H E X){ }^{(2)}$

Hypophosphatasia HPP (HPP, OMIM 146300, 241500, 241510 ) is a rare, progressive, hereditary, metabolic disease caused by the lack of activity of tissue-nonspecific alkaline phosphatase resulting from mutations in the ALPL gene encoding enzyme. ${ }^{(3,4)}$ This factor plays a crucial role in phosphate homeostasis and proper local regulation of mineralization. Poor cement mineralization leads to premature loss of primary and permanent teeth in HPP patients (Fig.1 c-d).
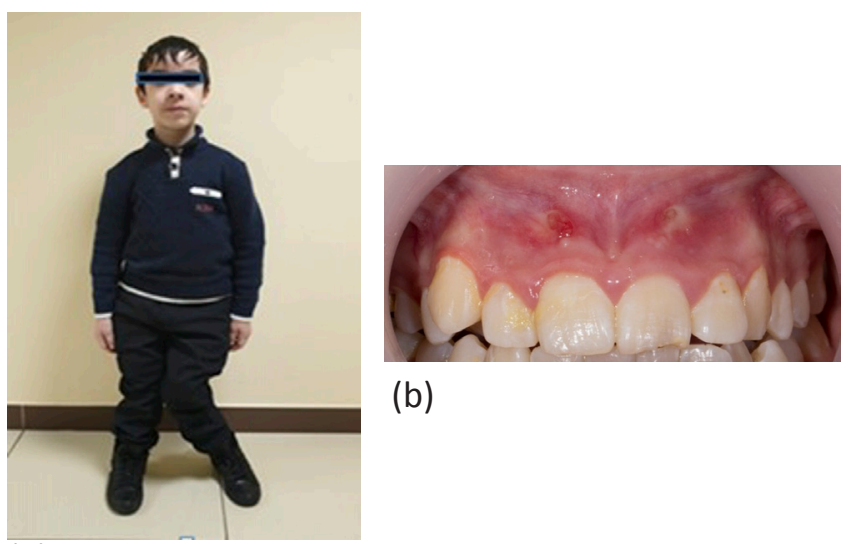

(b)

(a)

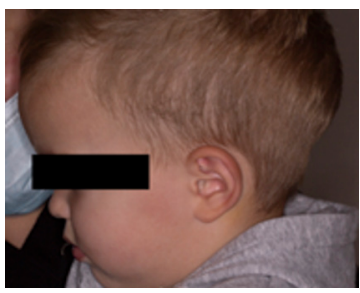

(c)

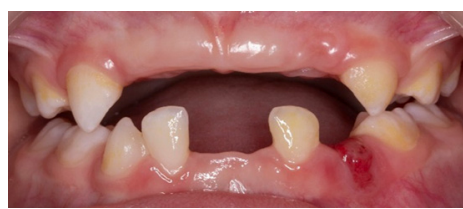

(d)

Fig. 1. Clinical features of XLHR and HPP. Skeletal pathology resulting from osteomalacia: Bowing legs in a 15-year-old patient with XLHR (a), skull deformities in a 4-year-old patient with HPP (c). Intraoral clinical picture: Periapical abscesses with sinus tracts in a 15-year-old patient with XLHR (b), premature loss of primary teeth in a 4-year-old patient with HPP (d).

According to the literature, detection of dental manifestations in patients with XLHR and HPP was most often based on the data from traditional radiological techniques, such as panoramic tomography and intraoral periapical radiography. ${ }^{(5,6)}$ With the presence of 3-D digital methods, such as cone beam computed tomography, diagnostic capabilities in dentistry have expanded significantly. CBCT has a few advantages over two-dimensional methods of examination. The high quality of diagnostic data obtained makes CBCT the method of choice for this cohort of patients. ${ }^{(7,8)}$ A crucial option of CBCT is the ability to quantify the mineralization level of the studied object.

\section{Materials and Methods}

The present study examined the results of scanning patients aged from 6 to 12 years (Group code 2_12 with mixed dentition) and from 12 to 18 years (Group code 218 with permanent dentition) with genetically and biochemically confirmed XLHR, and children aged from 12 to 18 years with genetically and biochemically confirmed HPP. The control groups (Group code 1_12 with mixed dentition and Group code 118 with permanent dentition) included CBCT data of children the same age examined for malocclusion in the Radiology Diagnostics Department at Moscow State University of Medicine and Dentistry named after AI Evdokimov. The scan protocol parameters are summarized in Table 1.

Table 1.

Scanning protocol using the KaVo OP $3 D$ Vision

\begin{tabular}{|c|c|c|c|c|c|c|c|}
\hline $\begin{array}{c}\text { Scanned } \\
\text { area }\end{array}$ & $\begin{array}{c}\text { FOV, } \\
\mathrm{cm}\end{array}$ & $\begin{array}{c}\mathrm{VD}, \\
\mathrm{mm}\end{array}$ & $\begin{array}{c}\mathrm{ST}, \\
\mathrm{sec}\end{array}$ & $\begin{array}{c}\mathrm{ET}, \\
\mathrm{sec}\end{array}$ & $\begin{array}{c}\text { Voltage, } \\
\mathrm{kV}\end{array}$ & $\begin{array}{c}\text { Amperage, } \\
\mathrm{mA}\end{array}$ & $\begin{array}{c}\mathrm{ED}, \\
\mathrm{E}, \mu \mathrm{SV}\end{array}$ \\
\hline $\begin{array}{c}\text { Maxillo- } \\
\text { facial }\end{array}$ & $16 \times 13$ & 0.25 & 26.9 & 7.4 & 120 & 5 & 0.011 \\
\hline
\end{tabular}

$V D$ - voxel dimensions; ST- scanning time; ET- exposure time; EDeffective dose

Data analysis was performed after constructing axial cross-sections using the software for visualizing computed tomography data i-CAT Vision. Morphometric parameters of teeth were studied, and mineral density of enamel, dentin, and alveolar bone was measured (Table 2). The presence, size and location of radiolucency, in relation to the surrounding anatomical structures, were evaluated.

Table 2.

Distribution of densitometric measurements in the study groups

\begin{tabular}{|c|c|c|c|c|c|c|}
\hline \multirow[t]{2}{*}{$\begin{array}{l}\text { Group } \\
\text { code }\end{array}$} & \multirow[t]{2}{*}{$\begin{array}{c}\text { Scans } \\
\text { (n) }\end{array}$} & \multicolumn{2}{|c|}{$\begin{array}{c}\text { Number of permanent } \\
\text { central upper incisors/ } \\
\text { densitometric } \\
\text { measurements } \\
\text { (HU) }\end{array}$} & \multicolumn{2}{|c|}{$\begin{array}{l}\text { Number of } \\
\text { permanent } \\
\text { first molars/ } \\
\text { densitometric } \\
\text { measurements } \\
\text { (HU) }\end{array}$} & \multirow[t]{2}{*}{$\begin{array}{l}\text { Alveolar } \\
\text { BMD } \\
\text { measure- } \\
\text { ments } \\
\text { (n) }\end{array}$} \\
\hline & & enamel & dentin & enamel & dentin & \\
\hline $\begin{array}{l}112 \\
\text { (Control } \\
\text { group) }\end{array}$ & 24 & $48 / 192$ & $48 / 192$ & $96 / 384$ & $96 / 384$ & 96 \\
\hline $\begin{array}{l}212 \\
(\bar{X} L H R)\end{array}$ & 10 & $20 / 80$ & $20 / 80$ & $40 / 160$ & $40 / 160$ & 40 \\
\hline $\begin{array}{l}118 \\
\text { (C̄Control } \\
\text { group) }\end{array}$ & 67 & $134 / 536$ & $134 / 536$ & $268 / 1072$ & $268 / 1072$ & 268 \\
\hline $\begin{array}{l}218 \\
\text { (XLHR) }\end{array}$ & 17 & $34 / 136$ & $34 / 136$ & $68 / 272$ & $68 / 272$ & 68 \\
\hline $\begin{array}{l}318 \\
(\overline{\mathrm{H} P P})\end{array}$ & 3 & $6 / 24$ & $6 / 24$ & $12 / 48$ & $12 / 48$ & 12 \\
\hline $\begin{array}{l}\text { Total } \\
\text { number }\end{array}$ & 121 & $242 / 968$ & $242 / 968$ & $484 / 1936$ & $484 / 1936$ & 484 \\
\hline
\end{tabular}

The mineral density of enamel and dentin was determined in Hounsfield units (HU) as the mean value of 4 areas of the tooth crown. All the first molars and upper central incisors were measured at 4 points (mesial, distal, buccal, and lingual/palatal) 
encompassing as large an area as possible, but without impinging on the images corresponding to the pulp. Densitometric measurements of the alveolar bone were performed in the furcation all first molars, but without impinging on the images corresponding to the periodontal ligament. Plots with an area of $1 \mathrm{~mm}$ were evaluated (Figure 2).

The statistical analysis was performed using the statistical software Microsoft Excel.
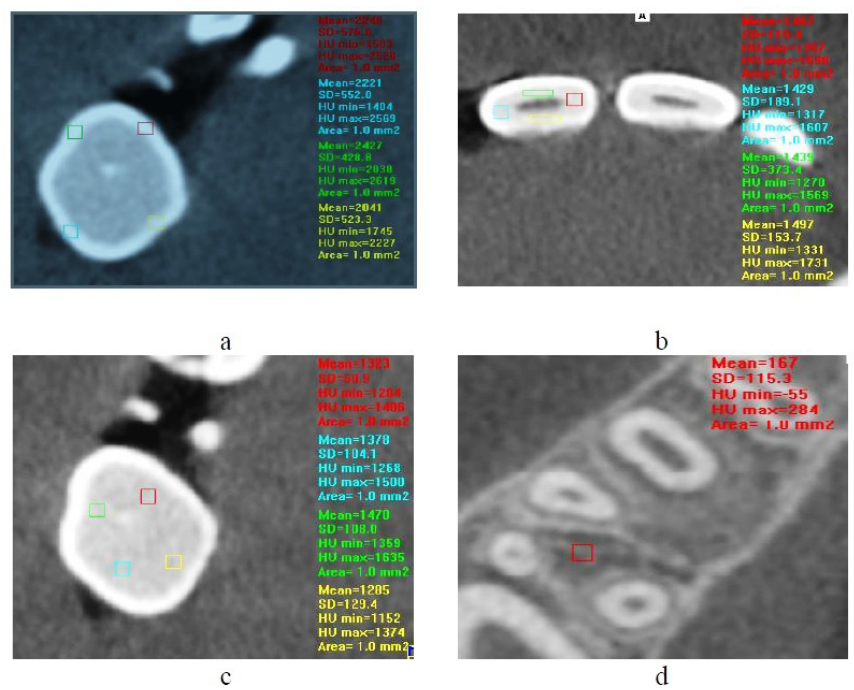

Fig. 2. CBCT. Axial cross-section. Mineral density measurements of the enamel of the first permanent molar (a); dentin of the upper central permanent incisor (b); dentin of the first permanent molar (b); alveolar bone (d) using the software for visualization of computer tomography data of the maxillofacial zone i-CATVision.

\section{Results}

The images of all XLHR and HPP patients visualized large pulp chambers with prominent pulp horns extending to the dentin-enamel junction (Figure 3).

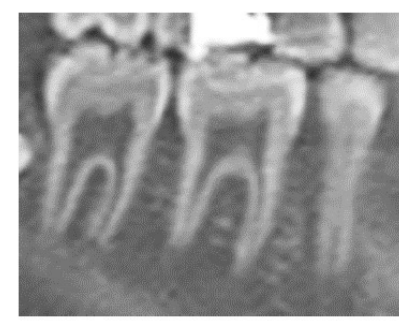

(a)

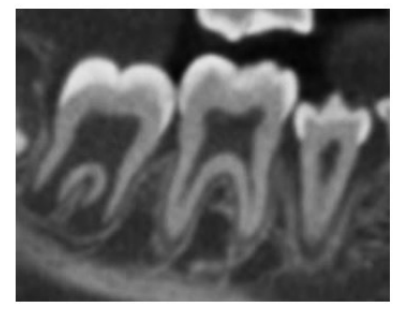

(c)

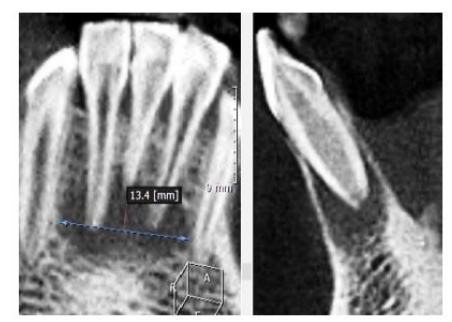

(b)

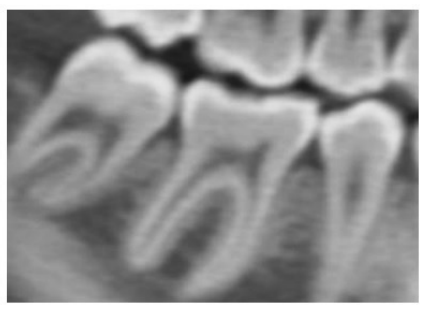

(d)
Fig. 3. CBCT. Mandible cross-sections in the lateral and frontal area: A 14-year-old HLHR patient $(a, b)$. A 13-year-old HPP patient (c); $a$ 14-year-old teenager of control group (d). Enlarged pulp chambers with prominent pulp horns extending to the dentin-enamel junction, alveolar bone hypodensity in XLHR and HPP patients. The large periapical lesion in the area of apparently healthy teeth in XLHR-patient (b).
There were no statistically significant differences in the enamel mineral density of the first permanent molars and central incisors in the comparison groups (Figure 4).

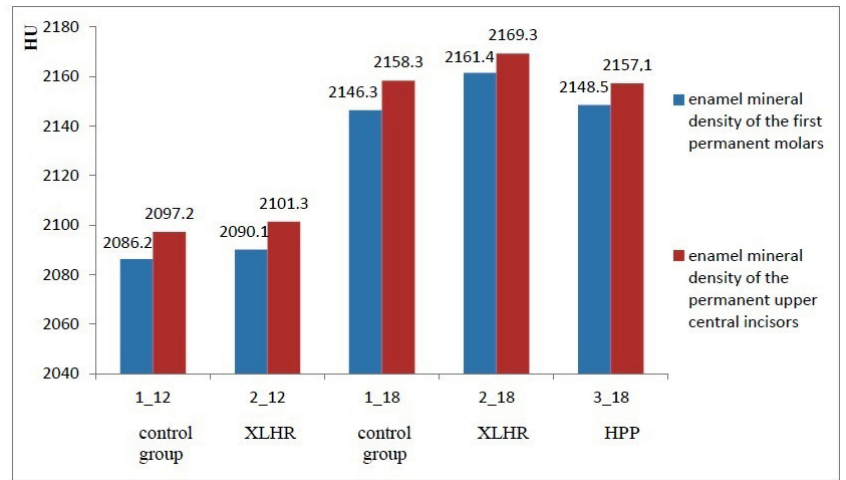

Fig. 4. Mean value of enamel mineral density in the study groups $(P>0.05)$

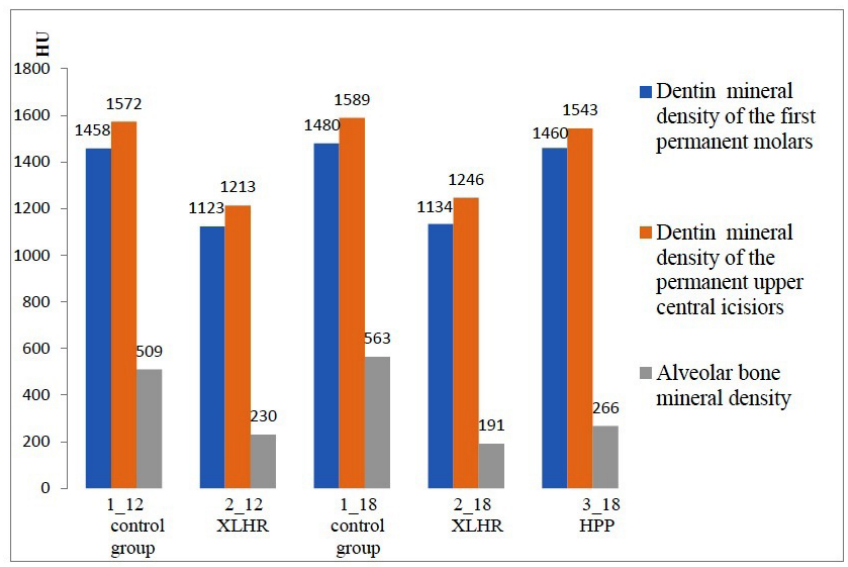

Fig. 5. Mean values of the dentin and alveolar bone mineral density in the study groups $(P<0.05)$

Dentin and alveolar BMD, on the contrary, revealed a statistically significant difference in the study groups (Figure 5).

Thus, according to the results of the study, in the XLHR group of children from 6 to 12 years (Group 2_12), the mean value of dentin mineral density (DMD) of the permanent first molar and upper central incisor was $1123 \pm 108 \mathrm{HU}$ and $1213 \pm 120$ $\mathrm{HU}$, respectively, which is significantly lower than in the control group (Group 1_12), where the corresponding indicators were $1458 \pm 148 \mathrm{HU}$ and $1572 \pm 124 \mathrm{HU}$. The difference in the DMD of the first permanent molars averaged $335 \mathrm{HU}$ (23\%), and the difference in the DMD of the permanent upper central incisors was $359 \mathrm{HU}(22.8 \%)$.

The same trend was observed in the XLHR group of children from 12 to 18 years (Group 2_18). The mean value of DMD of the first molar and upper central incisor was $1134 \pm 146$ $\mathrm{HU}$ and $1346 \pm 136 \mathrm{HU}$, respectively. In the control group of

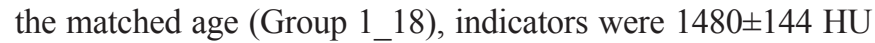
and $1589 \pm 149 \mathrm{HU}$, respectively. In this age group, the average difference in the DMD of the first molars was 346 HU (23.4\%), and the difference in the DMD of the permanent upper central 
incisors was $343 \mathrm{HU}(21.6 \%)$. The values of DMD in the same age group of HPP patients were almost identical to those in the control group. For the first molars, the value averaged $1460 \pm 91$ $\mathrm{HU}(1.4 \%$ less $)$, and for the upper central incisors, it averaged $1543 \pm 92 \mathrm{HU}(2.9 \%$ less $)$.

The alveolar BMD in the XLHR group of children from 6 to 12 years (Group 2_12) averaged 230 $290 \mathrm{HU}$, and in the control group of the matched age $509 \pm 89 \mathrm{HU}$. The difference in alveolar BMD in these groups averaged 279HU. In the older age group, the alveolar BMD in the control group (Group 1_18), the group of XLHR children, and the group of HPP children (Group 3_18)averaged $563 \pm 100 \mathrm{HU}, 191 \pm 78 \mathrm{HU}$ (66.1\% lower than in the control group), and $266 \pm 40 \mathrm{HU}$ (52.8\% lower than in the control group), respectively.

It is well known that the measurements of the mineral density in Hounsfield units evaluated by CBCT data are in a significant range and depend on a number of factors: technical parameters of equipment, human factor, etc. ${ }^{(9)}$ There is an objective need for additional validation of data.

To solve the above problem, it is proposed to use the option of comparing the relative mineral density indexes of different tissues for each individual scan. In a range of tissues - enamel, dentin and alveolar bone-the highest density, according to CBCT, is determined in enamel, the lowest in alveolar bone.

Literature data, which are confirmed by our results, indicate that the mineral density of enamel in patients with XLHR and HPP approximately matches the level in the group of healthy children. ${ }^{(10)}$ Thus, we evaluated the dentin and alveolar bone mineralization relative to the mineral density of enamel in each individual patient scan, and then compared these indexes.

The next indexes were calculated from the CBCT data of each patient in the group: of DMD

Ked=mean value of enamel mineral density/mean value

$\mathbf{K e a}=$ mean value of enamel mineral density/mean value of alveolar BMD

Then the group mean indexes, Ked and Kea, were calculated. For the second version of calculating these indexes obtained earlier mean values of enamel, dentin and alveolar bone density in the groups were used (Figure 4,5). The comparison of indexes is summarized in Table 3.

Table 3.

Mean values of indexes in the study groups

\begin{tabular}{|l|c|c|c|c|}
\hline \multicolumn{1}{|c|}{ Group code } & $\begin{array}{c}\text { Ked } \\
\text { mean } \\
\text { value } \\
\text { (version 1) }\end{array}$ & $\begin{array}{c}\text { Ked } \\
\text { mean } \\
\text { alue } \\
\text { (version 2) }\end{array}$ & $\begin{array}{c}\text { Kea } \\
\text { mean } \\
\text { value } \\
\text { (version 1) }\end{array}$ & $\begin{array}{c}\text { Kea } \\
\text { mean } \\
\text { value } \\
\text { (version 2) }\end{array}$ \\
\hline $\begin{array}{l}\text { 1_12 } \\
\text { (Control group) }\end{array}$ & 1.52 & 1.38 & 4.23 & 4.11 \\
\hline 2_12(XLHR) & 2.20 & 1.79 & 11.41 & 9.11 \\
\hline $\begin{array}{l}\text { 1_18 } \\
\text { (Control group) }\end{array}$ & 1.53 & 1.40 & 4.21 & 3.82 \\
\hline 2_18(XLHR) & 2.16 & 1.82 & 12.03 & 11.34 \\
\hline 3_18 (HPP) & 1.53 & 1.43 & 10.13 & 8.09 \\
\hline
\end{tabular}

Analyzing the indexes obtained by different methods, we can trace the following trend: the mineral density of dentin relative to the density of enamel in patients with hypophosphatasia and in the control group is approximately equal - 1.38-1.53 times less. At the same time, in XLHR patients, DMD is 1.79-2.20 times lower than the enamel mineral density. Alveolar BMD in patients with HPP and XLHR is 8.09-12.03 times lower than the enamel mineral density, while in control group the difference is only 3.82-4.23 times.

\section{Discussion}

After a comparative analysis of the mineral density of calcified tissues, using different versions of calculation, we can draw the following conclusions: DMD in XLHR patients and alveolar BMD density in XLHR and HPP patients is significantly reduced, compared to healthy peers.

The present study data correlate with the results of several authors who studied the enamel and DMD of teeth in XLHR and HPP patients. ${ }^{(11)}$

R.Pauwels et al. ${ }^{(12)}$ analyzed the reliability of estimating the mineral density of the studied objects in Hounsfield units according to CBCT data, compared with multi-detector computed tomography data. Van Dessel et al. ${ }^{(13)}$ did not find a statistically significant difference in the assessment of the structure and quality of the alveolar bone by CBCT and computed microtomography and concluded that the CBCT method is sufficiently accurate and informative for these purposes.

The teeth of XLHR patients are characterized by enlarged pulp chambers and root canals. The layer of hard tissues-enamel, dentin and cement, on the contrary, is thinner than normal. The horns of the pulp are located extremely high and can reach the enamel-dentine junction. Skrinar reported that enlarged pulp chambers were found in $24 \%$ of children and $52 \%$ of adults. ${ }^{(14)}$ According to our data, all images of XLHR and HPP patients visualized such abnormalities as large pulp chambers with prominent pulp horns extending to dentin-enamel junction.

The pathognomonic sign of the XLHR is periapical abscesses located in the area of the apparently healthy teeth with no history of trauma. Multiple, spontaneous, periapical abscesses pose special challenges to pediatric dentists, both in diagnosis and treatment, and are often the cause of primary and permanent teeth extractions in XLHR patients. Mineralization abnormalities of the dentin also may compromise the prognosis of endodontic treatment.

The cement and alveolar bone abnormal structure caused by reduced mineralization due to a lack of alkaline phosphatase activity leads to a poor tooth attachment and its subsequent premature loss in HPP patients. ${ }^{(15)}$ According to our data, the alveolar BMD is reduced in adolescents with hypophosphatasia. However, there are not enough data for unambiguous conclusions. Unfortunately, it is not possible to make a correct mineral density measurement of cement using CBCT data.

The relevance of the study was due to the search for objective criteria for assessing the level of enamel, dentin, and 
alveolar bone mineralization. In such cases, CBCT provides the most comprehensive amount of diagnostic information for clinicians. Data obtained could be used for planning dental treatment of patients with XLHR and HPP.

\section{Competing Interests} interests.

The authors declare that they have no competing

\section{References}

1. Opsahl Vital S, Gaucher C, Bardet C, Rowe PS, George A, Linglart A, Chaussain C. Tooth dentin defects reflect genetic disorders affecting bone mineralization. Bone. 2012 Apr;50(4):989-97. doi: 10.1016/j.bone.2012.01.010.

2. Lee BN, Jung HY, Chang HS, Hwang YC, Oh WM. Dental management of patients with X-linked hypophosphatemia. Restor Dent Endod. 2017 May;42(2):146-151. doi: 10.5395/ rde.2017.42.2.146.

3. Bianchi ML. Hypophosphatasia: an overview of the disease and its treatment. Osteoporos Int. 2015 Dec;26(12):2743-57. doi: 10.1007/s00198-015-3272-1.

4. Whyte MP. Hypophosphatasia: An overview For 2017. Bone. 2017 Sep;102:15-25. doi: 10.1016/j.bone.2017.02.011. 5. Sabandal MM, Robotta P, Bürklein S, Schäfer E. Review of the dental implications of X-linked hypophosphataemic rickets (XLHR). Clin Oral Investig. 2015 May;19(4):759-68. doi: 10.1007/s00784-015-1425-

6. Bloch-Zupan A. Hypophosphatasia: diagnosis and clinical signs - a dental surgeon perspective. Int J Paediatr Dent. 2016 Nov;26(6):426-438. doi: 10.1111/ipd.12232.

"Corresponding author: Dr. Elena V. Vislobokova. Pediatric Dentistry Department, Moscow State University of Medicine and Dentistry named after AI Evdokimov, Moscow, Russia. E-mail: visllena@yandex.ru
7. de Moura PM, Hallac RR, Seaward JR, Kane AA, Aguiar M, Raggio R, Gutfilen B. Objective and subjective image evaluation of maxillary alveolar bone based on cone beam computed tomography exposure parameters. Oral Surg Oral Med Oral Pathol Oral Radiol. 2016 May;121(5):557-65. doi: 10.1016/j.oooo.2016.01.019.

8. Yeung AWK, Jacobs R, Bornstein MM. Novel low-dose protocols using cone beam computed tomography in dental medicine: a review focusing on indications, limitations, and future possibilities. Clin Oral Investig. 2019 Jun;23(6):25732581. doi: 10.1007/s00784-019-02907-y.

9. Zhang J, Tian Y. Liu Y, Liu Q. Alveolar mineral density measurement using CBCT images. Neuroscience and biomedical engineering. 2017;5(1): 44-49. doi : 10.2174/2213385205666170612114301

10. Ribeiro TR, Costa FW, Soares EC, Williams JR Jr, Fonteles CS. Enamel and dentin mineralization in familial hypophosphatemic rickets: a micro-CT study. Dentomaxillofac Radiol. 2015;44(5):20140347. doi: 10.1259/dmfr.20140347.

11. Hayashi-Sakai S, Sakamoto M, Hayashi T, Kondo T, Sugita K, Sakai J, Shimomura-Kuroki J, Ike M, Nikkuni Y, Nishiyama H. Evaluation of permanent and primary enamel and dentin mineral density using micro-computed tomography. Oral Radiol. 2019 Jan;35(1):29-34. doi: 10.1007/s11282-018-0315-2.

12. Pauwels R, Jacobs R, Singer SR, Mupparapu M. CBCT-based bone quality assessment: are Hounsfield units applicable? Dentomaxillofac Radiol. 2015;44(1):20140238. doi: $10.1259 / \mathrm{dmfr} .20140238$.

13. Van Dessel J, Huang Y, Depypere M, Rubira-Bullen I, Maes F, Jacobs R. A comparative evaluation of cone beam CT and micro-CT on trabecular bone structures in the human mandible. Dentomaxillofac Radiol. 2013;42(8):20130145. doi: 10.1259/dmfr.20130145.

14. Skrinar A, Dvorak-Ewell M, Evins A, Macica C, Linglart A, Imel EA, Theodore-Oklota C, San Martin J. The Lifelong Impact of X-Linked Hypophosphatemia: Results From a Burden of Disease Survey. J Endocr Soc. 2019 May 7;3(7):1321-1334. doi: 10.1210/js.2018-00365.

15. Foster BL, Nociti FH Jr, Somerman MJ. The rachitic tooth. Endocr Rev. 2014 Feb;35(1):1-34. doi: 10.1210/er.2013-1009. 